\title{
Observational Study of the Multisciplinary team role (MDT) on Healthcare Management of Cancer Patients: Benefits and Barriers, AbuDhabi 2017
}

DOI: https://doi.org/10.32007/89018-24

\author{
Ibtisam H. Al Obaidi* $\quad$ FICMS
}

c) (7) (8)

This work is licensed under a Creative Commons Attribution-NonCommercial 4.0 International License.

Abstract:

Background: Multidisciplinary team meetings (MDTs) are designed to optimize patient outcomes. It appears intuitive that MDTs are essential to clinical decision-making and patient management; however, it is unclear whether that belief is supported by evidence. With regard to cancer patients, studies demonstrated that treatment plans made by interacting health care professionals are more effective than those made by individual practitioners.

J Fac Med Baghdad 2019; Vol.61, No.1 Received: April 2019 Accepted: July 2019 Published: July 2019
Objectives: To assess the impact of multidisciplinary teams (MDTs) on clinical decision-making and patient outcomes.

Methods: We follow a descriptive questionnaire survey study design and created a (10) sections surveymonkey that was distributed via email to (150) experts in surgical oncology, general surgery, oncology, radiation oncology, pathologists, and administrative staff. Fourty (40) completed responses were collected to ensure a statistical basis on which to draw sound conclusions. The remaining 110 staff have submitted incomplete answers. Answers were discussed in a separate MDT meeting with most of the participants. The survey was followed by an interpretation of the respondents' results and comparison with literatures.

Results: $75 \%$ of the participants chose "Agree and strongly agree", supporting the hypothesis that MDT meetings ensure an effective and up-to-date management guidelines. This means that the risk of not discussing a cancer patient cannot be neglected any longer. So the hypothesis statement (H0) is rejected and the alternative statement (Ha) is accepted.

Conclusions: The majority of participants saw the value in the MDT process and expressed support for its implementation locally and nationally; however, feedback about the most appropriate format is yet to be established. The clinicians identified the need for agreed standards in MDT performance.

Keywords: MDT meetings,MDM,MDC multidisciplinary care,cancer care.

\section{Introduction:}

MDTs management of cancer patients can result in a more effective treatment plans, MDMs also lead to increased communication between disciplines that are useful for training junior doctors(1). Although MDMs generate many benefits, the meetings do not always lead to optimum decision-making as outcomes have been found to be highly inconsistent and largely dependent on the effective participation of the team members $(2,3)$. Health professionals in attendance could be radiologists, pathologists, medical oncologists, surgeons and supportive care professionals (4). Our aim is to further understand the process, participation and operations of cancer MDT meetings in three private hospitals in $\mathrm{Abu}$

* Central Public Health Laboratory CPHL, Ministry of Health,bhazeez@gmail.com
Dhabi based on the experience and knowledge of participants. In a longitudinal study with a large cohort of cancer patients, Shulman et al and Slavova et al demonstrated that treatment plans made by interacting health care professionals are more effective than those made by individual practitioners $(5,6,7)$. In addition to more effective treatment plans, Lamb et al, Balasubramanian and Caudron et al found that MDMs also led to increased communication between disciplines that are useful for training junior doctors $(8,27,28)$. Shulman et al also found that specialists from one discipline understand the possibilities and constraints of other disciplines when exposed to other disciplines through MDMs.

Prades et al, Soukup et al and Hahlweg et al found that many participants in an MDM setting reported 
large amount of time was wasted due to disagreements between participants. However, the same survey revealed that participants were still positive about the outcome of MDMs and believed that it led to better plans for care $(9,24,26)$. Although, MDMs are clearly a group decisionmaking process, few studies have explored MDM processes and outcomes from the perspective of group reasoning. Some participants dominate due to their authority or charisma; not all information may be fully shared. Venod, Pillay et al, Harris et al, Carlson and Soukup et al. found that a lack of proper communication and interpersonal interaction could account for $70-80 \%$ of errors in health care $(10,11$, $22,23,25)$. As a communication process, an MDM cannot readily be evaluated using the same approach as medical interventions. This view is consistent with that held by Saini et al and Nguyen et al who found that information technologies in health care were often inappropriately evaluated using randomized clinical trial methodologies $(12,29)$.

Objectives: Our aim was to further understand the process, participation and operations of cancer MDT meetings in three private hospitals in Abu Dhabi based on the experience and knowledge of the participants. Our objective was also to identify obstacles to effective and sustainable MDT meetings, particularly how information and communication with the minimum set of conditions required for effective multidisciplinary case conferencing.

\section{Methods}

A questionnaire survey method (study design) used to verify the alternative hypothesis of MDT meetings benefits. The correlational method was mainly used to get a statistical test to find and rate patterns between organizational factors and opinions of decision makers (clinicians) being responsible for patient management.

The survey instrument created using Survey Monkey account on www.surveymonkey.com. This service is very easy to use and an unlimited number of participants can answer. The service is also free of charge. After the survey is finished, the results are made available in a spreadsheet format, which allows analysis, and report generation. The survey was pilottested with three users who were not included in the main study to get their feedback on the survey itself (length, clarity, and time to complete). Survey Monkey stored all respondents' data electronically, which was exported to Microsoft Excel for analysis purposes. Respondents were not identified in any way, and the survey was completely anonymous.

Timing and duration: The survey was announced to participants a few days in advance and then the target group received an email with details regarding the survey at the end of June 2017. The survey consisted of 10 questions. The time needed to complete the survey did not exceed 10 minutes. The participants were not involved in the design of the survey. Survey Participants: The MDM participant were health care professional who had participitated in at least one meeting during the past six months from the date of the survey, and non-MDM participants were those who had not attended any meeting (2). Of the 150 survey respondents, 40 were MDM experienced participants who submitted complete answers as they were regularly attending the MDT meetings. Thus, the results presented are based on the responses of those who were regularly present in the meetings during the past six months prior to answering the survey questionnaire. The selection of experienced participants was very important in order to get high quality results. This process was performed manually to ensure that only cancer experts selected from all three hospitals, were able to participate. The questions within all parts of the questionnaire aimed to gather qualitative as well as quantitative answers. Qualitative method has the advantage that participants can answer quickly since answers are pre-defined and can be selected with one click only. Most answers are based on a Likert-type scale. The applied Likert-scale includes five-level Likert items, from "absolutely disagree" to "absolutely agree" [Tables 1-2] (2). The last part consists of open questions with open text fields, which the participants could use to give additional comments and recommendations on the subject.

Survey Questionnaire:

Section 1: Biography of participants (age, specialty, years of experience and MDT meeting involvement). Section 2: MDT meetings and the communication patterns used.

Section 3: Follow up activities after MDT meetings (booking investigations and following up results or notifying patients of the meeting recommendations). Section 4: The communications technology of increasing information can support the physicians' role and reduce the time taken in conducting an MDT.

Section 5: Increasing the amount of information and how communication technology support physicians role to reduce the time taken per patient in the conduct of the meeting.

Section 6: How patient-related data and information are documented during the meeting (written by hand / entered electronically).

Section 7: How much of physicians' time is involved in follow up activities for the meetings attended on average? (less than 30 minutes - 4 hours per meeting. 
Section 8: How long is each patient discussed on average.

Section 9: Opportunities to examine the workload on MDT participants when there is an excessive number of patients who require an additional or re-discussion at the MDT meetings (when the right staff were not present or the right information was not available). Section 10: MDT meetings current practices and the extent to which the clinician concurs with the statements provided.

Answers were measured by a scale from 1-5.

\section{Results}

The majority of respondents (75\%) agreed about benefits of MDMs being the proper approach to improve cancer care, with only $5 \%$ having some form of disagreement. More than two thirds (67.5\%) of participants agreed that MDMs are not a waste of time, while $10 \%$ think they are a waste of time. The opinion of "Successful MDT meetings are based mostly on the leadership of the meeting" reveals that
$67.5 \%$ of survey participants felt that the leaders of the meetings were effective in not wasting time during the meetings. Participants noted the high number of staff involved in conducting an MDM and raised the issue of cost effectiveness of these meetings; $(72.5 \%)$ of respondents agreed with the opinion: "(MDTs) meetings are cost effective" as in (Table 1). An analysis of answers to the question (How long is the average time for each case discussion?) is shown in (Figure 1). The answers illustrate that most cases are only discussed for around 5-10 minutes, and that rarely is a case discussion last for more than 30 minutes. Participants' opinions on the time required to document the discussion being either during or after the MDMs, are shown in (Table 2). Minimal usage of direct entry into electronic devices for documentation in was agreed by $15 \%$ of resondents compared to $70 \%$ prefering manual data recording.

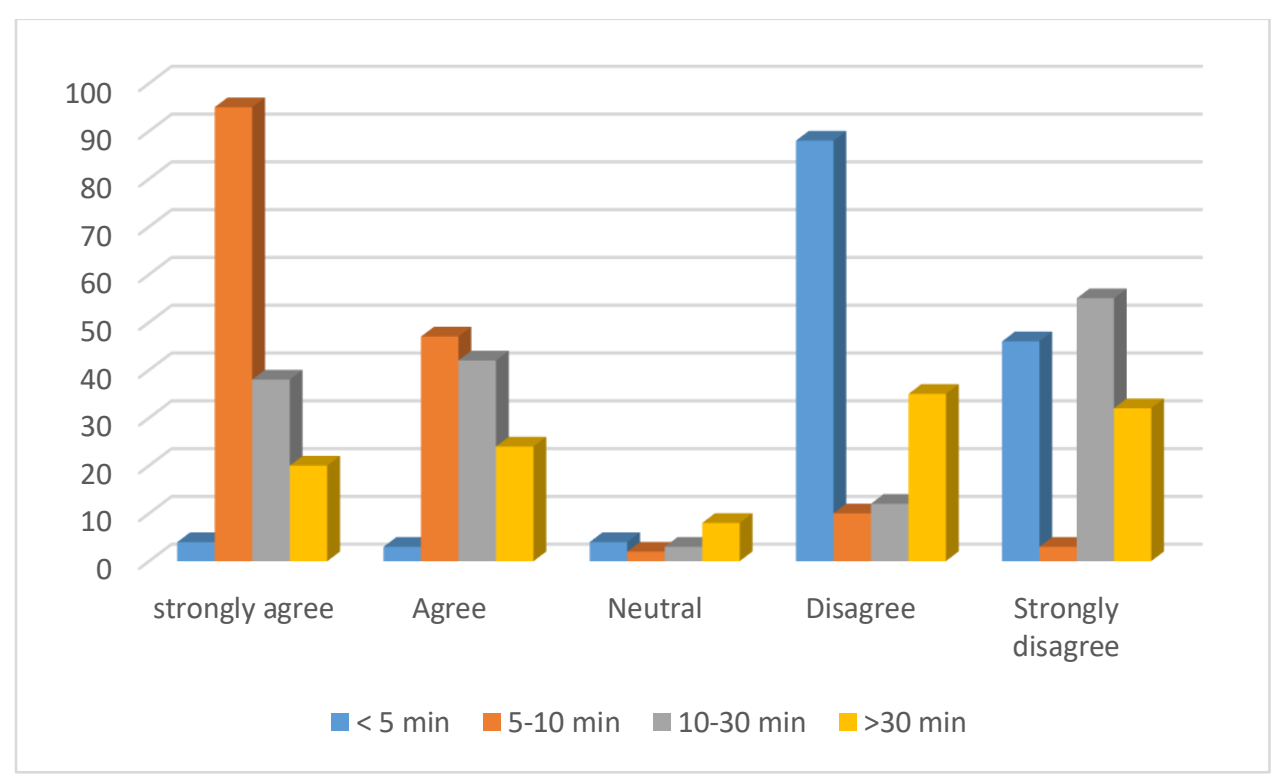

Figure 1. Average time allocated for each case discussion, majority of responces agree on 5-10 minutes

Table 1. Participants' opinions on MDMs impact on the standard of cancer care

\begin{tabular}{lllllll}
\hline Participants' opinions $(\mathrm{N}=40)$ & $\begin{array}{l}\text { Strongly } \\
\text { disagreed } \\
\text { No. }(\%)\end{array}$ & $\begin{array}{l}\text { Disagree } \\
\text { No. }(\%)\end{array}$ & $\begin{array}{l}\text { Neutral } \\
\text { No. }(\%)\end{array}$ & $\begin{array}{l}\text { Agree } \\
\text { No. }(\%)\end{array}$ & $\begin{array}{l}\text { Strongly } \\
\text { Agree } \\
\text { No. }(\%)\end{array}$ & $\begin{array}{l}\text { Skipped } \\
\text { No. }(\%)\end{array}$ \\
\hline $\begin{array}{l}\text { MDTs improve the } \\
\text { quality of care }\end{array}$ & $1(2.5)$ & $1(2.5)$ & $5(12.5)$ & $3(7.5)$ & $27(67.5)$ & $3(7.5)$ \\
\hline $\begin{array}{l}\text { I do not believe MDTs are a passing } \\
\text { fad }\end{array}$ & $1(2.5)$ & $3(7.5)$ & $4(10.0)$ & $7(17.5)$ & $20(50.0)$ & $5(12.5)$ \\
\hline MDTs are cost effective & $2(5.0)$ & $3(7.5)$ & $4(10.0)$ & $9(22.5)$ & $20(50.0)$ & $2(5.0)$ \\
\hline
\end{tabular}


Table 2: Participants' opinions on time duration required in MDM documentation

\begin{tabular}{llllll} 
Participants' opinions (N=40) & $\begin{array}{l}\text { Strongly } \\
\text { disagreed } \\
\text { No. }(\%)\end{array}$ & $\begin{array}{l}\text { Disagree } \\
\text { No. }(\%)\end{array}$ & $\begin{array}{l}\text { Neutral } \\
\text { No. }(\%)\end{array}$ & $\begin{array}{l}\text { Agree } \\
\text { No. }(\%)\end{array}$ & $\begin{array}{l}\text { Strongly } \\
\text { Agree } \\
\text { No. }(\%)\end{array}$ \\
$\begin{array}{l}\text { Long time to document all the } \\
\text { relevant case data DURING the } \\
\text { meeting }\end{array}$ & $20(50.0)$ & $5(12.5)$ & $4(10.0)$ & $1(5.0)$ \\
$\begin{array}{l}\text { Long time to document all the } \\
\text { relevant case data AFTER meeting }\end{array}$ & & $20(50.0)$ & $11(27.5)$ & $5(12.5)$ & $1(2.5)$ \\
\hline
\end{tabular}

\section{Statistical Analysis:}

using Chi-square test for agreement among clinicians on the value of MDT, where hypothesis is: H0: MDT meetings have no impact on cancer patients management. Ha: MDT meetings have an impact on cancer patients management.

\section{Discussion:}

Responding clinicians noted the beneficial added value of the MDM approach to their work and management. Participants' opinions on MDMs role in upgrading the standard of cancer care was supportive in $75 \%$ of participants. One answer mentioned "(MDMs) are very informative and educational, giving a greater understanding of pathology and its impact on treatment options". There were various reasons mentioned as to why MDMs were possibly not as effective or efficient as they could be. A frequent remark about the workload when too many cases were being discussed at a meeting, and enough time was not given to any one case treatment plan. Our results show that most patients are only discussed for about 5-10 minutes, and that rarely a case can be discussed for more than half an hour. This is not inconsistent with the observation that there is no enough time allocated to discuss the plan for patient treatment. However, this finding would suggest that MDMs are not seen as inefficient. Some may have the belief that MDMs are a waste of time, and do not need to be taken seriously, but it is clear from the results that this was not true for the majority of the participants. Despite some negative feedback, most of the objective data collected indicate a strong support in the potential utility of MDMs $(14,15,30,31)$. As one participant claimed "The MDMs often lead to delay in decision making, even though an incorrect decision is less often made". It is clear that participants would like to observe the scientific guidelines that proves the outcome of MDMs and view a reduction in inefficiencies that have been noted $(13,16,32,33)$. Cost effectiveness of these meetings are confirmed by $72 \%$ of respondents (agreed or strongly agreed) that (MDTs are cost effective). Some feedback indicated that many MDMs become side talks and that time should be more effectively allocated for actually examining patients face-to-face. There was a little difference in the responses on whether a long time is required to document all the
Computation of the expected frequency counts, the Chi-square $\left(\mathrm{X}^{2}\right)$ statistics and the degree of freedom (DF). The result reveals a P-value $<0.05$, which means we have to reject the null hypothesis (H0) and accept the alternative hypothesis (Ha) to conclude that there is an acceptable level of agreement on MDTs impact.

relevant case data DURING the meeting or AFTER the meeting with more responses favoring documentation during the meeting. Review of literatures reveals that our observations were in parallel with regards to MDT workload. Haward et al. (17) described a systematic assesment of the effectiveness of breast cancer team. The researchers evaluated the workload, team organization and working methods. Workload was defined as "new cancer annual caseload of the team related to the actual time committed by each breast team member" (17). It was found that team workload predicted the clinical effectiveness of the team positively. Their results also reinforced British guidelines that sufficient workload is required for viability and effectiveness of breast cancer teams. Nouraei et al (18) studied the increase of the efficiency of the MDT process in the head and neck tumour cases at Charing Cross Hospital in England. After conducting a systems analysis of this process, the researchers renewed the process and created a new data management solution to implement the process. Efficiency on-the-whole was improved by $60 \%$ as found from follow-up evaluation of the process. Kane et al (19) studied work processes and determined time demands for radiologists and pathologists at a hospital in Ireland. Their method addressed the documentation and analysis of all work connected with MDMs involving pathology and radiology in a particular month. Results of their study included:

- "Time spent at meetings, and in preparation for MDT meetings is significant"

- "The exchange of patient materials with outside institutions is a cause for concern when full data are not made available in a timely fashion."

The most recent and most closely related work to our study is that of Pillay et al (11). There was limited evidence for improved survival outcomes of patients discussed at MDT meetings. Between $4 \%$ and $45 \%$ of 
patients discussed at MDT meetings experienced changes in diagnostic reports following the meeting. Patients discussed at MDT meetings were more likely to receive more accurate and complete pre-operative staging, and neo-adjuvant/ adjuvant treatment. The conclusion from this study highlighted the impact of MDT meetings on patients' assessment and management practices. However, there was little evidence indicating that MDT meetings resulted in an improvements of patient survival. This also supports our reslts of $75 \%$ of respondents agreeing on the benefits of MDMs and the proper approach to improve cancer care rather than survival $(20,21)$. Our literature review shows that MDT meetings are important to clinical decision-making and patient management [Croke and El-Sayed 2012] (4) because they provide an opportunity for health care professionals to review cases, re-evaluate radiology and pathology reports, and discuss various treatment options (4). There is also strong evidence to show that MDT significantly influence clinical decision-making, and it is not a waste of time. This was consistent with our findings that $68 \%$ of opinions do believe the same.

\section{Conclusion:}

There is a recognized and well-supported growing value of MDTs in the clinical decision-making that lead to changes in diagnoses and physician management decisions. However, no strong evidence to support the opinion that they improve patient outcomes.

\section{Recommendations:}

A well-designed prospective study has to be carried out to provide proof of principle (Value of MDTs). MDTs is a peer review of cancer cases that is feasible and acceptable to recognize further development and to refere to a national benchmarking of MDTs against established outcome measures is required if this process is to be widely implemented. Concerns expressed by participants highlight the need for systematic quality improvement (QI) processes such as the peer-review process to be endorsed at a jurisdictional and executive level, and for there to be a commitment to provide teams with the appropriate resources and support necessary to conduct the MDT reviews and implement relevant recommendations. If peer review is adopted, a process for monitoring the implementation of recommendations needs to be established, otherwise uptake may be limited. It would be of great interest to further study this new model implemented in our medical institute, as in Baghdad Medical city by undertaking more observations from the team, whether through surveys, interviews, or task force groups. Further study would enable support of additional improvements to the multi-disciplinary team meeting model, so as to establish universal effectiveness in the goal of caring for patients with cancer.

\section{References}

1. Albreht T, Audisio $R$, "Policy statement on multidisciplinary cancer care" , European J of cancer, 2014, vol 50, (3): 475-480.

2. Bain C, Gitesh KR, . "Multi-disciplinary team meetings for cancer care: Results of an Australian Survey" J Cancer Research and Treatment, 2013 Vol. 1,( No. 1, 12-23).

3. Vishakha S, Stranieri A. "Group decision making in health care: A case study of multidisciplinary meetings" , J Decision Systems, 2016, 25:sup1,(476485).

4. Croke J, El-Sayed S. "Multidisciplinary management of cancer patients: Chasing a shadow or real value? An overview of the literature" . Current Oncology, August 2012; Volume 19, Number 4.

5. Chang JH. "The impact of a multidisciplinary breast cancer center on recommendations for patient management" : The University of Pennsylvania Experience. J Cancer 2001; 91: (1231-1237).

6. Shulman T, Bain C., "Obstacles to sustaining cancer care multidisciplinary team meetings: An australian survey". J Research in cancer and tumor, 2013; 2 (1): 10-21.

7. Slavova N, Azmanova S, Johnson CE. "Peer review of cancer multidisciplinary teams: Is it acceptable in Australia?" J. MJA February 2015; 202 (3) p144.

8. Lamb BW, Rozh TJ." Strategies to improve the efficiency and utility of multidisciplinary team meetings in urology cancer care: A survey study", J. BMC Health Services Research, 2014; 14:377.

9. Prades J, Remue E, Van Hoof E et al., "Is it worth recognizing cancer services on the basis of multidisciplinary (MDTs)? A systematic review of the objectives and organization of MDTs and their impact on patient outcomes". Health policy, 2015,vol.119 (4), 464-474.

10. Vinod SK, Sighom MA, Delaney GP. "Do multidisciplinary meetings follow guideline-based care?" J Oncol Practice 2010; 6 (6): 276-281.

11. Pillay B, Wootten A C, Crowe H. et al., "The impact of multidisciplinary team meetings on patient assessment, management and outcomes in oncology settings: A systematic review of the literature." Cancer treatment reviews, 2016; vol.42, 56-72.

12. Saini KS, Taylor C, Ramirez AJ et al. "Role of the multidisciplinary team in breast cancer management: Results from a large international survey involving 39 countries". J.Ann Oncol 2012; 23: 853-859.

13. Field KM, Rosenthal MA, Dimon $J$ et al., "Communication and clinician satisfaction with multidisciplinary team meetings in neuro oncology". J of clinical neuroscience, 2010, vol.17 (9): 1130-1135. 
14. Licitra L, Keilholz U, Tahara M et al., "Evaluation of the benefits and use of multidisciplinary teams in the treatment of head and neck cancer" . Oral oncology 2016; vol/59, 73-79.

15. Lan Y, Lin J, Jiang J., "Effects of a multidisciplinary team on colorectal cancer treatment" J. of surgery 2015; vol.48 (5): 145-150.

16. Valdagni A. "Multidisciplinary team meetings in cancer care : We could and should do better than this" . Clinical oncology, 2016; vol.28 (12), 799-800.

17. Haward R, Amir Z, Borrill C. et al. "Breast cancer teams: the impact of constitution, new cancer workload, and methods of operation on their effectiveness". British Journal of Cancer 2003.; vol.89: 15-22.

18. Nouraei S, Philpott J, Maude D. et al., "Reducing referral-to-treatment waiting times in cancer patients using a multidisciplinary database,". Annals of Royal College of Surgeons of England 2007; 89(2): 113-117.

19. Kane B, Luz S, O'Brian et al. , "Multidisciplinary team meetings and their impact on workflow in radiology and pathology departments". BMC Medicine 2006; 5(15). [Online]. Available:

http://www.ncbi.nlm.nih.gov/pmc/articles/PMC19193 90.

20. Walsh J, Harrison JD, Young JM. et al., "What are the current barriers to effective cancer care coordination? A qualitative study". BMC Health Service Research 2010; 10(132).

21. Scott F, Herve Ch, Leroy P. et al., "Supportive care organization in France : A national in depth survey among pateints and oncologists". Supportive care in cancer 2017; vol.25(7) 2111-2118.

22. Harris J, Taylor C, Sevdalis N. Z et al., "Development and testing of the cancer multidisciplinary team meeting observational tool (MDT-MOT)" . International J. for quality in health care, 2016; vol.28 (3), 332-338.

23. Carlson E."Collective wisdom and multidisciplinary tumor boards" . J of oral and maxillofascial surgery. 2014; vol.72(2): 235-236.

24. Soukup T, Petrides K, Lamb BW et al., "The anatomy of clinical decision- making in multidisciplinary cancer meetings. A cross-sectional observational study of teams in a natural context". Medicine (Baltimore) 2016; vol 95(24): e 3885.

25. Soukup T, Lamb BW, Sarkar S et al. "Predictors of treartment decisions in multidisciplinary oncology meetings: A quantitative observational study" .Ann Surg oncol 2016; vol 23 (13) : 4410-4417.

26. Hahlweg P, Didi S., Kriston L et al. "Process quality of decision- making in multidisciplinary cancer team meetings : A structured observational study". BMC cancer 2017; vol.17(1): 772.

27. Balasubramanian R, Subesinghe M, Smith JT. "The proliferation of multidisciplinary team meetings (MDTMs): How can radiology departments continue to support them all ?" Eur.Radiol. 2015; vol.25(12): 3648-3679.

28. Caudron A, Chaby $G$, Dadban A et al. "Multidisciplinary team meetings in oncology: First analysis of benefits and evaluation of activity in a dermatology unit in France" . Eur J Dermatol 2010; vol.20 (6): 778-784.

29. Nguyen NP, Vos P, Lee $H$ et al., "Impact of tumor board recommendations on treatment outcome for locally advanced head and neck cancer". J Oncology 2008; vol.75:186-191.

30. Cohen P, Tan AL, Penman A. "The multidisciplinary tumor conference in gynecologic oncology-Does it alter management?" Int J Gynecol Cancer 2009; vol.19:1470-1472.

31. Blazeby JM, Wilson L, Metcalfe C et al., "Analysis of clinical decision-making in multidisciplinary cancer teams". Ann Oncol 2006; 17:457-460.

32. Pawlik TM, Laheru D, Hruban RH et al., "Evaluating the impact of a single-day multidisciplinary clinic on the management of pancreatic cancer" . Ann Surg Oncol 2008; 15:20812088.

33. Kurtz JE, Heitz D, Serra S et al. , "Adjuvant chemotherapy in elderly patients with colorectal cancer. A retrospective analysis of the implementation of tumor board recommendations in a single institution" . Crit Rev Oncol Hematol 2010; vol.74:211-217. 
دور الفريق متعدد التخصصات في ادارة الرعاية الصحية لمرضى السرطان في ثلاث مستشفيات في ابو ظبي , الفوائد والمعوقات المرضى المرات

د. ابتسام حسين العبيدي

الخلاصة

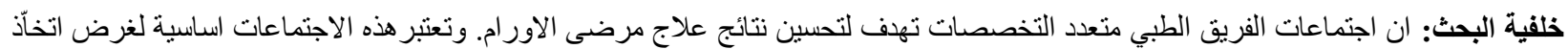

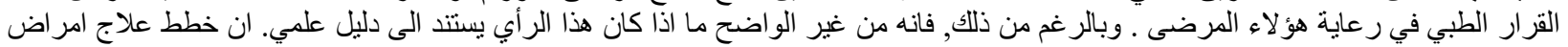

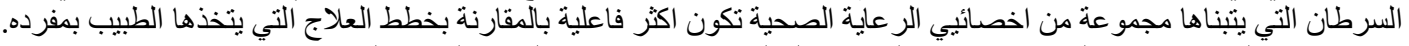

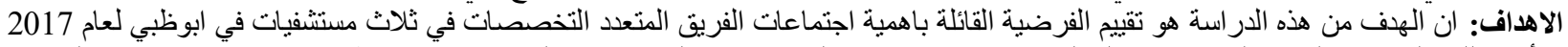

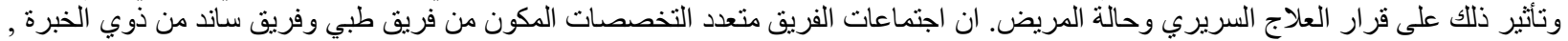

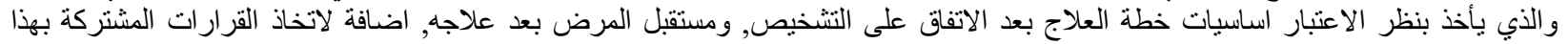

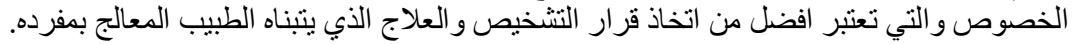

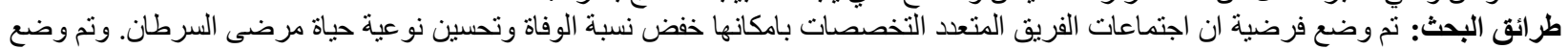

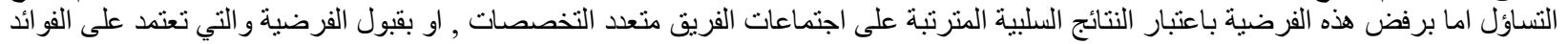

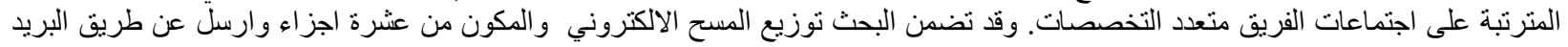

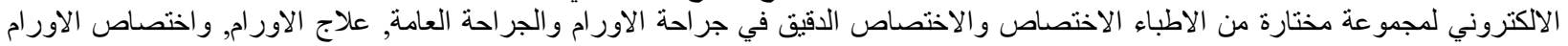

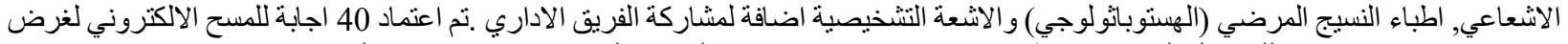

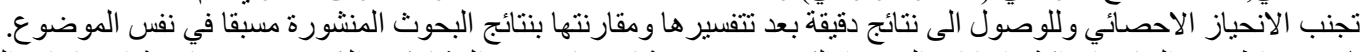

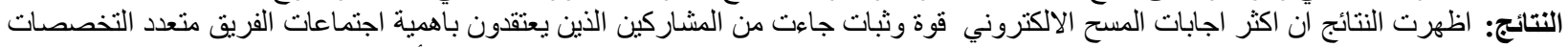

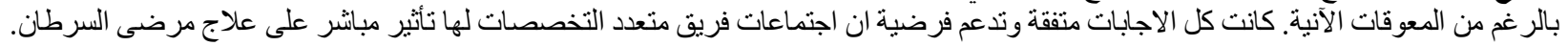

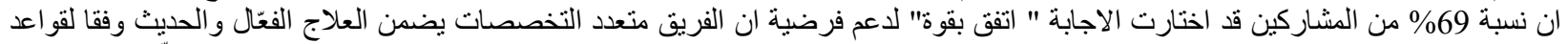

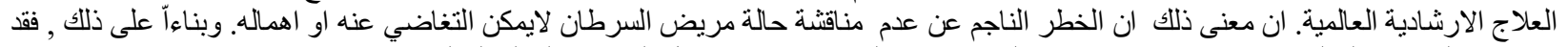

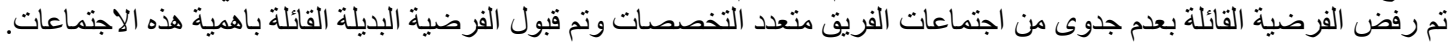

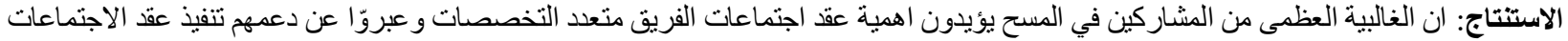

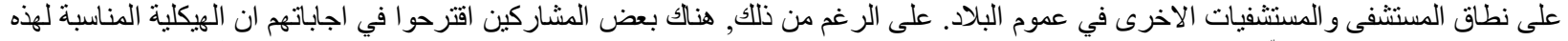

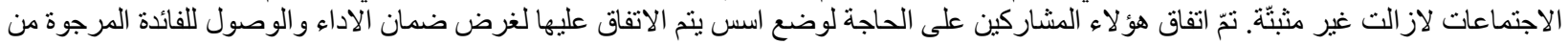

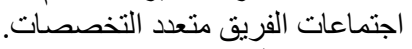
الكلمات الدالة: الفريق متعدد التخصصات, اجتماعات الفريق متعدد التخصصات, رعاية السرطان . 